\title{
Beriman kepada Allah SWT sebagai fitrah manusia dalam skrip drama 'Tiang Seri Tegak Berlima' karya Noordin Hassan
}

\author{
Believe in Allah SWT as a human nature in the scripts of 'Five Upright Pillars' drama \\ by Noordin Hassan \\ Intan Zahariah Gaisun \\ intanzahariahgaisun@gmail.com \\ Arba'ie Sujud \\ arbaie@putra.edu.my \\ Universiti Putra Malaysia, Serdang, Selangor, Malaysia
}

DOI: https://doi.org/10.37134/pendeta.vol10.1.2019

\begin{abstract}
ABSTRAK
Model teater fitrah merupakan satu kerangka dalam menentukan fitrah sesebuah teater. Dalam hal ini, model teater fitrah merupakan acuan daripada prinsip teater fitrah yang dikemukakan Noordin Hassan. Ironinya, model teater fitrah merupakan satu model yang telah dikembangkan bersandarkan kepada prinsip teater fitrah. Walau bagaimanapun, kedua-duanya (model dan prinsip) tetap menyalurkan konsep pementasan yang jitu berasaskan agama Islam. Oleh yang demikian, makalah ini bertujuan mengaplikasikan model teater fitrah terhadap drama "Tiang Seri Tegak Berlima" karya Noordin Hassan. Walau bagaimanapun, kajian ini hanya melihat berdasarkan kepada prinsip yang pertama sahaja iaitu beriman kepada Allah SWT dengan melihat watak dan perwatakan yang terdapat dalam skrip drama tersebut. Berdasarkan kajian lepas, kajian mengenai teater fitrah banyak dilakukan terhadap teater Noordin Hassan selepas munculnya konsep teater fitrah. Kebanyakannya menyentuh soal konsep teater fitrah tanpa mengaitkan dengan prinsip teater fitrah yang sebenarnya. Hal ini menurut Siti Jasmina Ibrahim (2012) menyatakan perjuangan teater fitrah tidak menyeluruh disambut oleh semua pengkarya, sebaliknya masih ramai yang samar pemahaman. Oleh yang demikian, kajian ini bertujuan menganalisis prinsip beriman kepada Allah SWT sebagai fitrah manusia terhadap drama 'Tiang Seri Tegak Berlima' karya Noordin Hassan. Kewajaran pemilihan ini dibuat memandangkan Rahmah Bujang (2002) menyatakan bahawa pertama kali Noordin Hassan menimbulkan kesan keislaman dalam arena teater tanah air adalah melalui drama 'Bukan Lalang Ditiup Angin'. Kajian ini merupakan kajian analisis teks tanpa menyentuh aspek pementasan. Hasil kajian mendapati teks 'Tiang Seri Tegak Berlima' merupakan teks yang mengaplikasikan prinsip beriman kepada Allah SWT di mana kemenangan berpihak kepada watak protagonis manakala watak antagonis tidak dimenangkan. Dalam hal ini, penyelesaian telah berpihak kepada kebaikan bagi memenangkan 'amal makruf nahi mungkar'.
\end{abstract}

Kata Kunci: Fitrah, Model Teater Fitrah, Noordin Hassan, Teater Melayu, 'Tiang Seri Tegak Berlima'

\section{ABSTRACT}

Theatre of faith (natural constitution) model is a framework in determining the nature of a theater. In this regard, the theatre of faith model is a molding of the faith theater principles by Noordin Hassan. Ironically, the theater of faith model is one that has been developed based on the faith theater principles. However, both (model and principles) still display the concept of staging based on Islamic religion. Therefore, this study applies the theatre of faith model in a theatre by Noordin Hassan entitled 'The Five Upright Pillars'. However, this study only looks at the first principle of believing in Allah SWT by looking at the characters found in the scripts. In previous studies, the theatre of faith is mostly explored in Noordin Hassan's theatres after the emergence of theatre of faith concept. Most of them stated on the concept of theater of faith without relating it to the principles of theater of faith. According to Siti Jasmina Ibrahim 
(2012), who stated that the theatre of faith was not hardly accepted by many performers because many of them barely understand the theatre of faith. Hence, this study aims to analyze the principles of faith in Allah SWT as a human trait in 'The Five Upright Pillars' by Noordin Hassan. The selection was made based on what Rahmah Bujang's (2002) statement which explained that the first time Noordin Hassan had an Islamic effect was through the play of 'Bukan Lalang Ditiup Angin'. This study focuses on the text and drama scripts analysis without analyzing the aspect of performance. The findings of the study indicated that the text of 'The Five Upright Pillars' was a text that applied the principle of faith to Allah Almighty in which victory was favored by the protagonist while the antagonist was not favored. In conclusion, the solution has been in favor on the winning side to acknowledge 'amal makruf nahi mungkar'.

Keywords: Faith, Model Theatre of Faith, Noordin Hassan, Malay Theatre, 'The Five Upright Pillars'

\section{PENGENALAN}

Tujuan manusia diciptakan adalah untuk beribadat kepada Allah SWT. Ini sebagaimana yang dinyatakan oleh Noordin Hassan (1983) bahawa tujuan hidup dalam Islam adalah untuk mencari keredaan Allah SWT kerana telah menjadi fitrah manusia untuk beriman kepada Allah SWT. Maka, sebagai khalifah di muka bumi-Nya, manusia hidup adalah untuk menghambakan diri dengan beribadah kepada Allah dalam pelbagai cara termasuklah melalui pengkaryaan. Dalam hal ini, pengkaryaan yang dinyatakan oleh Noordin Hassan adalah karya yang boleh menyeru manusia dengan hikmah dan hasanah supaya menyedari serta memenuhi tuntutan-tuntutan Islam sebagai tanda kesyukuran kepada Allah SWT. Ini dilihat selari dengan karya yang mengenengahkan pemikiran kerohanian. Dalam hal ini, Farra Humairah Mohd dan Nik Rafidah Nik Muhammad Affendi (2016) menyatakan dalam agama Islam, pemikiran kerohanian melihatkan hubungan dan komunikasi manusia secara vertikal iaitu manusia sebagai hamba sekali gus sebagai khalifah yang berhubungan terus dengan Allah SWT. Justeru, ini dilihat selari dengan Rahmah Bujang (2002) yang menyatakan karya Noordin Hassan mempunyai perwatakan yang memainkan peranan seperti drama-drama lain, iaitu melalui sesuatu keterujaan dan jatuh bangun kehidupan, tetapi bezanya ialah dalam karya beliau ciri-ciri tersebut terungkap dalam konteks hubungan manusia dengan Tuhannya.

Melihat kepada permulaan tercetusnya idea teater fitrah ini adalah ketika penglibatan Noordin Hassan dalam pertandingan musabaqah Al-Quran pada tahun 1400 Hijrah. Pertandingan ini menyedarkan beliau tentang konsep teater fitrah. Maka di sinilah bermulanya idea teater fitrah yang diserlahkan dalam teater *1400. Hal ini memandangkan Noordin Hassan (1983) menyatakan selepas beliau mempelajari sedikit sebanyak falsafah 'isme' dari Barat dan sekular, beliau berpendapat bahawa teori-teori hasil pemikiran manusia tidak boleh dipegang kerana teori-teori ini tidak kekal dan selalunya dipinda atau diketepikan oleh teori yang baharu pula. Maka, dengan itu, Noordin Hassan mula mencari-cari identiti teater yang berteraskan agama Islam. Dengan demikian, Noordin Hassan (1983) menyatakan sebagai orang Islam, yang kekal dan boleh dijadikan panduan buat selama-lamanya ialah Al-Quran dan hadis, bukan falsafah 'isme'. Maka dengan itu, lahirlah teater yang diberi nama teater fitrah.

Justeru, dalam konteks teater fitrah, nilai-nilai Islam mewarnakan struktur, bentuk, rubrik, dan bahasa teater. Dengan itu, karya tersebut dikatakan bertatasusilakan Islam dan indah berseni. Menelusuri konsep teater fitrah, terdapat enam prinsip dalam memahami konsep tersebut. Melalui prinsip inilah terbentuknya model teater fitrah. Prinsip tersebut adalah beriman kepada Allah SWT, matlamat kehidupan, akidah yang suci dan syariat yang betul, kesan beriman kepada Allah SWT, Menyediakan ruang atau jiwa yang universal dan penghabluran tanggapan. Keenam-enam prinsip teater fitrah tersebut merupakan satu pendekatan yang boleh memberi dan menunjukkan salah satu cara bagaimana drama dan teater apabila dibantu oleh teknik penulisan yang berpandukan sastera Islam, mampu menjadi alat untuk beribadat (Noordin Hassan, 1983). Walau bagaimanapun, kajian ini hanya melihat kepada prinsip yang pertama sahaja iaitu prinsip beriman kepada Allah SWT. Justeru, tujuan kajian ini adalah untuk menganalisis prinsip beriman kepada Allah SWT sebagai fitrah manusia dalam drama "Tiang Seri Tegak Berlima" karya Noordin Hassan. 


\section{KAJIAN LITERATUR}

Kajian ini akan terbahagi kepada dua bahagian iaitu kajian mengenai drama Tiang Seri Tegak Berlima dan konsep teater fitrah. Salman Al-Farisi (2017) dalam artikel yang bertajuk Perempuan Melayu dalam Tiang Seri Tegak Berlima Karya Noordin Hassan membincangkan posisi perempuan Melayu secara simbolik melalui watak Siti Muhsinat. Makalah ini menggunakan teori feminisme kritikal berdasarkan metode analisis naratif yang bersifat kualitatif sehingga menghasilkan temuan bahawa watak laki-laki menggunakan simbol budaya dan agama sebagai alat dominasi terhadap watak perempuan. Selain itu, Solehah Ishak (1989) dalam artikel bertajuk Aesthetics of Modern Malay Theatre Productions Which are predominantly Islamic in Themes membincangkan bagaimana drama dipersembahkan dalam bentuk teater berdasarkan estetika Islam. Terdapat dua perkara yang disampaikan oleh Solehah Ishak dalam kajiannya ini iaitu perubahan produksi teater Melayu Malaysia yang banyak menggunakan tema keislaman dalam persembahan mereka serta memperkatakan tentang percanggahan yang perlu dihadapi produksi teater Melayu yang bersifat keislaman. Artikel ini menggunakan karya Noordin Hassan termasuk Tiang Seri Tegak Berlima sebagai bahan kajian. Seterusnya, melihat kepada kajian mengenai konsep teater fitrah pula, Solehah Ishak (1995) dalam artikel Theatre Fitrah and "1400" * membincangkan tentang konsep teater fitrah dalam karya Noordin Hassan, 1400*. Karya ini dipilih kerana, Noordin Hassan dikatakan pertama kali menyerlahkan konsep teater fitrahnya dalam drama 1400. Hasil kajian mendapati konsep teater fitrah terserlah dalam drama 1400*. Seterusnya, kajian yang dilakukan oleh SM Zakir (2007), dalam artikel yang bertajuk Konsep Teater Fitrah dalam Teater Noordin Hassan membincangkan konsep teater fitrah dalam drama Noordin Hassan. Hasil kajian mendapati drama-drama Noordin Hassan mengikuti konsep teater fitrah dan memenuhi konsep qardan hasanan, aslama dan din.

Berdasarkan kajian lepas, kajian mengenai skrip drama "Tiang Seri Tegak Berlima" dan konsep teater fitrah banyak dilakukan. Kajian tersebut membincangkan tentang posisi watak perempuan Melayu dari teori feminisme, bentuk teater berdasarkan estetika Islam serta perbincangan mengenai konsep teater fitrah. Walau bagaimanapun, kajian mengenai pengaplikasian prinsip teater fitrah terhadap karya Noordin Hassan sangat kurang dilakukan. Hal ini kerana, ramai pengkaji hanya memberi tumpuan terhadap konsep teater fitrah secara umum tanpa mengenengahkan prinsip-prinsipnya selain melihat karya dari sudut teori barat. Hal ini sebagaimana yang dinyatakan oleh Siti Jasmina Ibrahim (2012), bahawa perjuangan teater fitrah tidak menyeluruh disambut oleh semua pengkarya, sebaliknya masih ramai yang samar pemahaman dan mungkin berasakan isme-isme Barat itu lebih maju, berani dan membuatkan mereka nampak lebih hebat. Oleh yang demikian, kajian ini bertujuan untuk menganalisis model teater fitrah dalam drama "Tiang Seri Tegak Berlima" karya Noordin Hassan memandangkan model teater fitrah itu terbentuk beracukan daripada prinsip teater fitrah itu sendiri. Walau bagaimanapun, kajian ini hanya akan melihat kepada prinsip yang pertama dalam model teater fitrah sahaja dan melihat dari segi elemen watak dan perwatakan. Pemilihan elemen ini dilihat sejajar dengan kehendak prinsip pertama dalam model teater fitrah tersebut. Selain itu, kewajaran pemilihan skrip drama ini dibuat memandangkan drama tersebut merupakan lanjutan drama "Bukan Lalang Ditiup Angin" di mana menurut Rahmah Bujang (2002), pertama kali Noordin Hassan menimbulkan kesan keislaman dalam arena teater tanah air adalah melalui drama "Bukan Lalang Ditiup Angin".

\section{METODOLOGI KAJIAN}

Kajian ini akan menggunakan model teater fitrah sebagai kerangka teori. Model teater fitrah terbina daripada acuan prinsip teater fitrah yang dikemukakan oleh Noordin Hassan pada tahun 1983. Walaupun model teater fitrah merupakan satu model yang telah dikembangkan bersandarkan kepada prinsip teater fitrah, kedua-duanya (model dan prinsip) tetap menyalurkan konsep pementasan yang jitu berasaskan agama Islam. Model teater fitrah menyalurkan enam prinsip utama iaitu beriman kepada Allah SWT, matlamat kehidupan, akidah yang suci dan syariat yang betul, kesan beriman kepada Allah SWT, 
menyediakan ruang atau jiwa universal serta penghabluran tanggapan. Kerangka teater fitrah ini didapati menawarkan prinsipnya yang paling penting iaitu memperakukan kefitrahan sesuatu teks mahupun pementasan drama. Walau bagaimanapun, kajian ini akan mengaplikasikan prinsip yang pertama sahaja iaitu beriman kepada Allah SWT. Dalam konteks kajian ini, prinsip yang pertama akan melihat kepada elemen watak-perwatakan dalam skrip drama "Tiang Seri Tegak Berlima" memandangkan prinsip ini sendiri akhirnya akan memihak kepada watak protagonis bagi memenangkan amal makruf nahi mungkar.

\section{Beriman Kepada Allah SWT}

Noordin Hassan (1983) mempercayai bahawa beriman kepada Allah SWT itu ialah fitrah manusia. Ini dijelaskan melalui watak perwatakan dalam sesuatu cerita. Ini dapat dilihat, sekiranya ada watak antagonis yang mempertikaikan konsep ini dalam perjalanan cerita (sekiranya drama itu ada cerita), penyelesaian haruslah memihak kepada protagonis, dan jangan dibiarkan tergantung atau "terbuka". Ini bermakna, penyelesaian harus berpihak kepada kebaikan bagi memenangkan 'amal makruf nahi mungkar'. Sehubungan itu, SM Zakir (2009) menyatakan maksud Noordin Hassan tentang konsep beriman kepada Allah SWT dilihat berlandaskan tujuan hidup dalam Islam. Menurut SM Zakir lagi, tujuan hidup dalam Islam adalah mencari keredhaan Allah SWT kerana menjadi fitrah manusia untuk beriman kepada Allah SWT. Dalam mencari keredhaan Allah SWT, seseorang haruslah mengikuti fitrah manusia itu sendiri. Dalam hal ini, Syed Muhammad Al-Naquib Al- Attas (2010) menegaskan setiap ciptaan Allah SWT menepati pola yang diciptakan-Nya iaitu sesuatu yang wujud semenjak manusia diciptakan. Dalam hal ini, fitrah merupakan satu hukum yang mana sekiranya manusia mengikuti fitrahnya akan berada dalam keadaan yang harmoni manakala manusia yang mengingkari fitrahnya akan menentang hukum yang telah ditetapkan itu dan akan berada dalam keadaan yang tidak menentu.

Sehubungan itu, dalam meletakkan diri seseorang berada dalam keadaan yang harmoni, manusia haruslah menepati pola yang diciptakan-Nya. Ini dapat dilihat berdasarkan pola fitrah sebagaimana yang dinyatakan oleh Abdul Mujid dan Jusuf Mudzajir (2002) iaitu berdasarkan daripada pentafsiran Al-Quran dan hadis dapat membangunkan beberapa jenis fitrah dan jenis fitrah ini membentuk satu pola fitrah. Dalam hal ini jenis-jenis fitrah yang wujud terhasil daripada pentafsiran ayat-ayat al-Quran dan hadis dalam konteks yang berbeza seperti yang diperlihatkan dalam pola fitrah seperti berikut:

1) Fitrah bermaksud suci (al-thuhr)

2) Fitrah bermaksud berpotensi Islam (al-din al-Islami).

3) Fitrah bermaksud mengakui keesaan Allah (tauhid Allah)

4) Fitrah bermaksud keadaan selamat (al-salamah) dan berterusan/lestari (istiqamah)

5) Fitrah bermaksud perasaan yang tulus ikhlas (al-ikhlas)

6) Fitrah bermaksud kesanggupan manusia untuk menerima kebenaran (isti'dad li qabul)

7) Fitrah bermaksud potensi dasar manusia untuk beribadat (syu'ur li al - ubudiyah) dan mengenal Allah.

8) Fitrah bermaksud, ketetapan atau takdir asal manusia mengenai kebahagiaan dan kesesatannya.

9) Fitrah bermaksud sifat-sifat Allah (asma'al-husna).

Berdasarkan pola fitrah tersebut, Abdul Mujid dan Jusuf Mudzajir (2002) menyatakan pola tersebut boleh dizahirkan oleh semua manusia tidak kira bangsa dan jantina dan mereka mempunyai pola fitrah yang sama. Menurutnya, fitrah merupakan satu hukum mengikut al-Quran dan hadis, dan ia mesti diaktualisasikan. Kegagalan dalam melaksanakannya akan memberikan kesan kepada kesejahteraan manusia itu.

Pendapat Abdul Mujid dan Jusuf Mudzajir ini dilihat selari dengan pendapat Syed Naquib Al-Attas (2010) yang menjelaskan 'fitrah' merupakan kepatuhan manusia dan segala ciptaan Allah SWT terhadap hukum-hukum alamiyah yang telah ditentukan-Nya banyak memberikan keharmonian hidup kepada manusia dan seluruh isi alam yang menjadi simbol ketaatan mereka terhadap Tuhannya. Sesungguhnya, keakuran dan tunduknya manusia terhadap tuntutan 'fitrah' ini turut melahirkan 'kepatuhan' dan 'ketaatan' yang tidak berbelah bahagi oleh manusia terhadap 'Perjanjian Azali' dengan Allah SWT iaitu untuk sentiasa 
melaksanakan perintah-Nya dan menjauhi segala larangan-Nya. Sesungguhnya kepatuhan dan ketaatan manusia yang tidak berbelah bahagi ini akan menyerlahkan konsep keimanan kepada Allah SWT; sejajar dengan prinsip pertama teater fitrah yang meletakkan prinsip mempercayai bahawa beriman kepada Allah SWT itu ialah fitrah manusia sebagai keutamaan dalam melahirkan teater fitrah yang berlandaskan keimanan. Justeru, untuk melihat kepatuhan dan ketaatan manusia yang tidak berbelah bahagi ini adalah melalui watak perwatakan seseorang dalam sesebuah drama. Melalui watak perwatakan inilah akan menentukan sama ada seseorang itu mengikuti pola fitrahnya sebagai seorang manusia yang akhirnya menuju ke arah kebaikan dan memenangkan amal makruf nahi mungkar atau sebaliknya.

\section{Aplikasi Model Teater Fitrah Terhadap Drama Tiang Seri Tegak Berlima}

\section{Sinopsis drama Tiang Seri Tegak Berlima}

"Tiang Seri Tegak Berlima" merupakan lanjutan drama "Bukan Lalang Ditiup Angin" tulisan Noordin Hassan. Naskhah ini ditulis sekitar tahun 1970-an yang mengetengahkan tema ketidakadilan sosial (Solehah: 1996). Ketidakadilan sosial tersebut wujud apabila golongan atasan mengeksploitasi golongan bawahan. Dalam hal ini, eksploitasi sesama manusia membawa pelbagai keburukan termasuklah membuat mereka yang tidak berkuasa mengsublimasikan diri, walaupun menggunakan agama sebagai 'saluran' atau penyaluran murni (Noordin Hassan: 2006). Ini melemahkan semangat bangsa dan negara. Apabila ini berterusan, maka berlanjutan pulalah eksploitasi. Oleh itu, sambil menasihati rakyat hidup berprinsip, mereka yang jadi kuasa haruslah berani dan tegas dalam percubaan membasmikan eksploitasi sesama manusia. Topik tersebut termasuk isu penting dalam naskhah teater "Tiang Seri Tegak Berlima". Menurut Solehah Ishak (1996) Tiang Seri Tegak Berlima merujuk Rukun Negara Malaysia yang diisytiharkan pada tahun 1970 yang menjadi teras perjuangan negara Malaysia dan diletakkan pada watak Siti Muhsinat. Kumpulan Kapak hadir sebagai representasi kekuasaan laki-laki tidak dapat dilepaskan daripada isu ketidakadilan sosial, terutama ketika dikaitkan dengan watak Siti Muhsinat yang menjadi korban atau mangsa.

\section{Siti Muhsinat}

Dalam skrip drama 'Tiang Seri Tegak Berlima', watak Siti Muhsinat ialah anak Pak Ku yang merupakan seorang muallaf. Walaupun Siti Muhsinat merupakan anak seorang muallaf, tetapi wataknya dapat dilihat menjurus ke arah kebaikan dan memenangkan amal makruf nahi mungkar. Ini dapat dilihat apabila Siti Muhsinat menzahirkan beberapa pola fitrah dalam skrip drama 'Tiang Seri Tegak Berlima'. Ini dibuktikan apabila Siti Muhsinat sering didatangi mimpi yang sama dan berasa takut akan mimpinya. Mimpi tersebut merupakan peringatan kepada manusia yang melakukan kesalahan. Dalam hal ini, Siti Muhsinat sebenarnya dikehendaki untuk menyampaikan dakwah kepada orang ramai agar hidup dalam perpaduan. Dalam adegan empat babak satu menunjukkan babak pergaduhan serta maki hamun antara lelaki I, II dan III. Tiba-tiba Pak Ngah dan Siti Muhsinat muncul lalu Siti Muhsinat menyampaikan perkara mimpi yang dialami dalam adegan lima babak satu. Sebenarnya Siti Muhsinat menyampaikan dakwah agar menegakkan perpaduan sesama manusia. Dalam hal ini, Siti Muhsinat menyatakan agar jangan mendedahkan keburukan sesama manusia.

Selain itu, Siti Muhsinat juga menyampaikan dakwahnya terhadap Hidayat agar kembali kepada Allah SWT. Ini dapat dilihat dalam adegan dua babak dua apabila Siti Muhsinat bertanyakan kepada Hidayat tentang tujuan hidupnya. Hidayat lalu menjawab untuk mengikuti jejak langkah ayahnya lantas Siti Muhsinat menyampaikan dakwahnya dengan menyampaikan lagu bertajuk Kintan. Ini dapat dilihat seperti dalam rangkap lirik berikut: 


\author{
KINTAN \\ Bila engkau menyuap nasi \\ Keringat siapa tumpah di bumi? \\ Bila engkau menjamah ikan \\ Isteri mana terlena sunyi? \\ Bila perajurit gugur di sempadan \\ Siapa tersedu diapa tersedan \\ Engkau diulit mimpi yang enak \\ Perwira kuyup di semak duri \\ Engkau tak payah bergelumang lumpur \\ Tak usah hanyut di gelombang hitam \\ Wahai Hidayat hiduplah berguna \\ Pesanan Kintan cabaran aku
}

(Halaman 251-252)

Berdasarkan lirik tersebut, adalah jelas bahawa Siti Muhsinat meminta Hidayat untuk menjadi orang yang berguna dalam hidup. Dakwah Siti Muhsinat ini akhirnya mendapat sambutan positif daripada Hidayat apabila Hidayat mula berfikir lalu bertanyakan kepada ayahnya tentang Tuhan yang disembah oleh ayahnya.

Sehubungan itu, penyampaian dakwah oleh Siti Muhsinat ini memperlihatkan bahawa Siti Muhsinat menzahirkan pola fitrah mengakui keesaan Allah SWT. Dalam hal ini, menyampaikan dakwah merupakan perkara yang mentauhidkan Allah SWT. Ini dapat dilihat dalam Surah Al-Muddaththir ayat 17 sebagaimana terjemahan berikut:

\begin{abstract}
"Wahai orang yang berselimut! Bangunlah serta berilah peringatan dan amaran (kepada umat manusia). Dan kepada Tuhanmu, maka ucaplah dan ingatlah kebesaran-Nya. Dan (pada) pakaianmu, maka hendaklah kamu bersihkan. Dan segala kejahatan, maka hendaklah engkau jauhi. Dan janganlah engkau memberi (sesuatu dengan tujuan hendak) mendapat lebih banyak daripadanya. Dan bagi (menjalankan perintah) Tuhanmu, maka hendaklah engkau bersabar (terhadap tentangan musuh)."
\end{abstract}

(Surah Al-Muddaththir: ayat 1-7)

Berdasarkan petikan ayat surah Al-Muddaththir ini jelas membawa maksud dan matlamat yang mendalam serta kesan dan tindakan yang bersungguh-sungguh tentang matlamat perintah memberikan peringatan, matlamat membesarkan Tuhan, matlamat membersihkan pakaian dan menjauhi segala kejahatan supaya mencapai pembersihan zahir dan batin, dan juga bermaksud membersihkan jiwa dari sebarang keburukan dan cemar sehingga sampai ke tahap sempurna dan matlamat tidak mengharapkan balasan yang banyak dengan pemberiannya. Sehubungan itu, matlamat-matlamat yang dinyatakan tersebut secara ringkasnya adalah untuk mentauhidkan Allah SWT. Maka, Siti Muhsinat dilihat mengaktualisasikan pola fitrah mengakui keesaan Allah SWT.

Seterusnya, Siti Muhsinat juga dilihat menzahirkan pola fitrah keadaan selamat (al-Salamah) dan berterusan/lestari (istiqamah). Ini dilihat apabila Siti Muhsinat menjadikan Rukun Negara sebagai panduan untuk hidup berharmoni. Dalam hal ini, Rukun Negara signifikan sebagai satu falsafah bagi negara Malaysia agar kaum-kaum yang tinggal di negara ini hidup berharmoni, saling menghormati dan tolongmenolong antara satu sama lain. Ini digambarkan semasa Siti Muhsinat berada dalam tahanan, Siti Muhsinat telah menyampaikan lagu yang bertajuk Musafir kepada orang-orang tahanan sebagai memujuk mereka agar tidak risau dengan situasi tahanan mereka. Ini dapat digambarkan sebagaimana lirik berikut: 


\author{
MUSAFIR \\ Musafir, kita musafir \\ Mengharung duri dalam jalanan \\ Hingga sampai apa yang dituju \\ Balik pada Rukun Berlima \\ Mencari tetap mencari \\ Ditelan kabut dipuncak gunung \\ Baru hidup punyai erti \\ Keadilan, harapan kita. \\ Beriman pada yang Maha Esa \\ Daulat watan kasihi negara \\ Aturan hidup penuh susila \\ Balik pada Rukun Berlima.
}

(Halaman 257-258)

Berdasarkan lirik tersebut, adalah jelas bahawa Siti Muhsinat menjadikan Rukun Negara sebagai panduan untuk terus hidup berharmoni dan keadilan merupakan satu harapan untuk dicapai. Sehubungan itu, Siti Muhsinat menjadikan Rukun Negara sebagai panduannya untuk hidup berharmoni tanpa ada eksploitasi daripada mana-mana pihak. Dalam hal ini, Abdul Mujib (1999) memetik sebuah hadis qudsi daripada Abu Umar Ibn 'Abd. Al-Bar yang menjelaskan sebagaimana terjemahan berikut:

"Sesungguhnya Aku (Allah) menciptakan hamba-hamba-Ku dalam keadaan selamat yang panjang. Maka setanlah yang menarik pada keburukan".

Mengikut Abu Umar Ibn 'Abd. Al-Bar, fitrah tidak mengenali Allah atau mengingkari-Nya hinggalah manusia itu baligh atau boleh berfikir. Maka asalnya, fitrah bererti keselamatan dalam proses penciptaannya, watak dan strukturnya. Dengan kata lain, mengikut fitrahnya, manusia diciptakan dalam keadaan selamat yang berpanjangan. Walau bagaimanapun, keselamatan tidak akan lestari apabila manusia itu masuk ke dalam perangkap syaitan. Sehubungan itu, petunjuk daripada al-Quran dan hadis sangat perlu untuk kelestarian keselamatan manusia. Dalam hal ini, Rukun Negara juga mengetengahkan rukun kepercayaan kepada Tuhan. Dalam konteks kajian ini, Siti Muhsinat menzahirkan konsep kepercayaan kepada Tuhan itu sebagai beriman pada yang Maha Esa.

\title{
Hidayat
}

Hidayat merupakan anak Ketua Kumpulan Kapak (KKK) yang hidupnya adalah bertujuan untuk mengikuti jejak langkah ayahnya. Hidayat pada awalnya seorang yang zalim namun sesuai dengan namanya Hidayat, beliau menerima hidayah kebenaran dan akhirnya menuju ke arah kebaikan. Ini terjadi dengan bantuan penyampaian dakwah Siti Muhsinat yang mempersoalkan tujuan hidupnya di dunia ini dengan menyampaikan lirik lagu bertajuk KINTAN. Setelah mendengar lirik lagu tersebut, Hidayat telah menerima hidayah untuk mendapat kebenaran. Setelah menerima hidayah, Hidayat lalu menyoal ayahnya tentang Tuhan yang disembah oleh ayahnya serta cukai yang dibayar oleh ayahnya. Perkara yang ditanya itu sebenarnya adalah berkaitan dengan rukun Islam iaitu sembahyang lima waktu sehari serta menunaikan zakat.

Sehubungan itu, Hidayat dilihat menzahirkan pola fitrah kesanggupan manusia untuk menerima kebenaran. Dalam hal ini, Abdul Mujib (1999) menyatakan konsep fitrah ini adalah berlandaskan surah Yunus ayat 90 yang bermaksud sebagaimana terjemahan berikut: 
"Lalu Firaun dan bala tenteranya menyusul mereka untuk menindas dan menumpas, sampai tatkala ia hampir mati kelelap. Ia berkata: Aku percaya bahawa tak ada Tuhan selain Dhat yang para putera Israel beriman kepada-Nya, dan aku adalah golongan orang yang Muslim”.

(Surah Yunus: 90)

Daripada maksud surah Yunus tersebut dapat disimpulkan bahawa secara fitrah manusia berusaha mencari kebenaran walaupun pencarian itu masih tersembunyi dalam hati yang paling dalam. Inilah yang dipaparkan pada watak Hidayat apabila beliau menerima kebenaran Islam setelah bersoal jawab dengan Siti Muhsinat mengenai tujuan hidup di dunia.

Seterusnya, Hidayat juga dilihat menzahirkan pola fitrah ketetapan atau takdir asal manusia mengenai kebahagiaan dan kesesatannya. Dalam hal ini, Hidayat dilihat memilih untuk mengikuti perjuangan Siti Muhsinat untuk mencapai keadilan bagi orang-orang yang tertindas. Hidayat tidak memilih untuk terus bersama ayahnya yang merupakan Ketua Kumpulan Kapak. Hidayat dilihat menggunakan akal fikiran untuk memilih ketetapan atau takdir asalnya sama ada untuk memilih kebahagiaan atau kesesatan. Dalam hal ini, Hidayat memilih untuk mengikut perjuangan Siti Muhsinat dengan memilih bahagia memandangkan perjuangan Siti Muhsinat adalah untuk mencapai keadilan manakala perjuangan ayahnya adalah untuk menindas golongan-golongan yang lemah.

Sehubungan itu, Abdul Mujib dan Jusuf Mudzajir (2002) menyatakan mengikut Islam, secara fitrah, manusia boleh menjadi baik atau jahat dan bergantung kepada kegiatan atau tindakan manusia sendiri. Ini dapat dilihat berdasarkan surah al-Syams, ayat 9-10 sebagaimana terjemahan berikut:

"Sesungguhnya beruntung orang yang menumbuhkan jiwanya dan sungguh rugi orang yang menguburkannya"

(Surah Al-Syams: Ayat 9-10)

Maka adalah jelas, manusia boleh membuat pilihan sama ada menjadi baik atau sebaliknya dan manusia bebas memilihnya. Dalam hal ini, Hidayat telah memilih untuk menjadi baik dan sekaligus mengaktualisasikan pola fitrah ketetapan atau takdir asal manusia mengenai kebahagiaan dan kesesatannya.

\section{Mek Bongsu}

Watak Mek Bongsu dalam skrip ini dilihat sangat merendah diri dan tahu akan tanggungjawabnya sebagai seorang insan. Dengan sikapnya itulah menunjukkan bahawa Mek Bongsu sedar akan fitrahnya sebagai seorang manusia. Dalam hal ini, Mek Bongsu merupakan seorang yang sangat bertuah kerana hidupnya sangat senang. Hidupnya diulit dengan kemewahan sehingga tidak tahu akan kesusahan orang ramai di luar 'Taman Kencana'. Walau bagaimanapun, Mek Bongsu akhirnya tersedar akan tanggungjawabnya terhadap orang yang susah. Akhirnya, Mek Bongsu membuat keputusan untuk meninggalkan segala kemewahan yang ada dan menjadi golongan marhaen untuk membantu golongan yang susah. Ini dapat dilihat berdasarkan petikan dialog dan puisi berikut:

PAK NGAH: Apa yang terjadi? Ha! Tinggallah Mek dalam Taman Kencana. Hujankah, panaskah, Mek tak perasan. Menguningkah padi, Mek tak tau. Keringkah telaga; Mek tak sedar. (Agak nakal). Mek diulit, d-a-n, Mek mengulit. Sungguh senang tak buat apa. (Dengan nada yang berlainan). Tapi akhirnya, Mek tersedar: 
Mek Bongsu sedih terharu,

Jari halus memohon ampun;

Sungguh malu dalam mahligai

Jadi marhaen membawa wahyu.

(Halaman 232)

Berdasarkan petikan dialog dan puisi tersebut jelas memperlihatkan Mek Bongsu meninggalkan segala kemewahan dan kesenangan yang diperolehinya semata-mata mahu membawa wahyu. Dalam hal ini, perkara 'membawa wahyu' itu merupakan menolong orang yang susah dan melaksanakan tanggungjawabnya sebagai seorang manusia. Mek Bongsu tersedar akan hal ini apabila orang-orang yang daif hadir ke majlis hari lahir Mek Bongsu dengan membawa harapan untuk diterima bekerja di tempat Mek Bongsu. Kesedaran Mek Bongsu akan tanggungjawabnya ini seiring dengan pola fitrah potensi dasar manusia untuk beribadat.

Sehubungan itu, pola fitrah potensi dasar manusia untuk beribadat ini merupakan fitrah manusia. Dalam hal ini, manusia diperintah untuk beribadat kepada Allah dan mengenali-Nya. Maksud fitrah ini diambil daripada surah Yasin, ayat 22 sebagaimana terjemahan berikut:

"Dan alasan apakah yang aku punyai jika aku tak mengabdi kepada Tuhan yang menciptakan aku dan kepada-Nya kamu akan kembalikan”.

(Surah Yasin: Ayat 22)

Dalam diri manusia sebenarnya terdapat satu potensi kebenaran (dinnullah). Sekiranya seseorang menggunakan potensinya ini, maka akan sentiasa berjalan di atas jalan yang lurus kerana Allah SWT telah membimbingnya sejak di alam ruh (dalam kandungan) lagi. Menurut Ibnu Taimiyyah, potensi dasar manusia dibuat oleh Allah atas dasar naluri dan kecenderungan tauhid, iaitu naluri kepatuhan dan mengabdi kepada Allah tanpa ada kemusyrikan.

Seterusnya, Mek Bongsu juga dilihat menzahirkan pola fitrah perasaan yang tulus ikhlas. Hal ini dapat dilihat apabila Mek Bongsu ikhlas menolong golongan daif dengan meninggalkan segala kesenangan yang dimiliki. Setelah Mek Bongsu tersedar dengan kesusahan dan keadaan golongan daif, Mek Bongsu terus memeluk seorang perempuan yang buta dan menyentuh lelaki yang capik. Mek Bongsu merasa sangat sedih melihat keadaan orang-orang daif sedangkan Mek Bongsu hidup senang lenang. Tindakan Mek Bongsu inilah yang memperlihatkan keikhlasan Mek Bongsu dalam membantu golongan daif. Ini dapat diperlihatkan seperti dalam petikan berikut:

(Nyata benar MEK BONGSU sudah mula terharu dengan kata-kata dan keadaan mereka ini. MEK BONGSU memerhati mereka penuh mesra dan keharuan. Air mata mula mengalir. MEK BONGSU sedang menahan kesebakan didadanya. Orang-orang daif juga turut terharu dengan perasaan yang ternyata di wajah MEK BONGSU. MEK BONGSU merapati seraya memeluk seorang perempuan yang buta; disentuhnya lelaki yang capik. Nyanyian orang-orang daif ini menjadi agak lantang dan beremosi).

(Halaman 234)

Berdasarkan petikan tersebut, adalah jelas bahawa Mek Bongsu ikhlas menolong orang-orang daif. Pada awalnya Mek Bongsu merasa sedih dengan keadaan golongan daif dan akhirnya Mek Bongsu turun bersama-sama mereka untuk membantu mereka. Dalam hal ini, manusia difitrahkan mempunyai sifat-sifat yang baik dan antara sifat baik itu ialah tulus ikhlas dalam melaksanakan segala kegiatan. Dalam sebuah hadis daripada Abd Hamid yang dipetik dari Abdul Mujib (1999) ada menyatakan bahawa: 
"Tiga perkara yang menjadikan keselamatan, iaitu ikhlas berupa fitrah Allah yang manusia diciptakan daripadanya, solat berupa agama dan taat berupa perisai".

(Abdul Mujib: 27)

Di sini, fitrah dihubungkan dengan keikhlasan dan keikhlasan nyata sangat penting dalam membentuk keperibadian Islam yang sejati.

\section{Ketua Kumpulan Kapak (KKK)}

Dalam prinsip yang pertama ini, Noordin Hassan (1983) menyatakan sekiranya ada watak antagonis yang mempertikaikan konsep ini dalam perjalanan cerita (sekiranya drama itu ada cerita), penyelesaian haruslah memihak kepada protagonis. Dalam Tiang Seri Tegak Berlima, KKK adalah ayah kepada Hidayat. Dalam drama ini, KKK merupakan watak antagonis yang sering menindas orang yang lemah. Ini digambarkan apabila KKK telah berkahwin dengan gadis muda dan masih mentah. Walau bagaimanapun, pada hari persandingannya, KKK tidak muncul dan menghantar sebatang kapak yang cukup besar dan diperbuat daripada kayu sebagai gantinya untuk bersanding dengan pengantin perempuan. Dalam hal ini, kapak tersebut merupakan lambang keluarga dan keturunan KKK. Perkara tersebut telah membuatkan Mak Andam dan Siti Muhsinat marah dan menegur wakil KKK yang membawa kapak kerana menganggap KKK telah menghina pengantin perempuan. Maka berlakulah kekecohan di majlis tersebut lalu wakil KKK menangkap pengantin perempuan dan Siti Muhsinat untuk bertemu dengan KKK. Ini dapat dilihat melalui dialog berikut:

MAK ANDAM: Ha, mana dia pengantin laki-laki?

WAKIL: Saya telah diwakili menyampaikan salam (selaku berpidato) dan memaklumkan, pengantin laki-laki tak dapat hadir; dan sebagai gantinya untuk bersanding, inilah dikirimkan lambang keluarga dan keturunan. Sila ke depan. (Sebatang kapak yang cukup besar-diperbuat daripada kayu dipayung masuk; disandingkan dengan pengantin perempuan; majlis menjadi ribut; terdengar suara MAK ANDAM)

MAK ANDAM: Saudara Wakil; si gadis ini naik pelamin Cuma sekali sahaja dalam penghidupan dia. Apa ini?

WAKIL: Saya Cuma menjalankan tugas

SITI MUHSINAT: Saudara harus merasa malu menjalankan tugas seperti ini.

(Halaman: 247-248)

Berdasarkan petikan dialog tersebut, adalah jelas bahawa KKK telah menghina pengantin perempuan dengan menghantar sebatang kapak sebagai ganti dirinya dalam persandingannya sendiri. KKK tidak memikirkan perasaan pengantin perempuan dan keluarga pengantin perempuan yang malu dengan tindakannya menggantikan dirinya dengan sebatang kapak. Inilah yang dikatakan penghinaan sesama manusia.

Pada akhirnya, watak KKK telah tewas dan melarikan diri. Ini dapat dilihat berdasarkan petikan dialog berikut:

LEFTENAN NATHAN: Kediaman Ketua Kumpulan Kapak telah pun ditawan; banyak pengikut-pengikutnya yang terbunuh. Tetapi, Ketua Kumpulan Kapak terlepas lari.

(Halaman: 259)

Berdasarkan petikan dialog tersebut, adalah jelas bahawa watak antagonis yang mempertikaikan konsep teater fitrah dalam perjalanan cerita akhirnya penyelesaian tidak memihak kepada mereka. 


\section{KESIMPULAN}

Berdasarkan huraian yang dibuat, dapat dilihat bahawa drama Tiang Seri Tegak Berlima mengaplikasikan prinsip pertama dalam model teater fitrah. Dalam hal ini, watak Siti Muhsinat menzahirkan pola fitrah mengakui keesaan Allah SWT dan pola fitrah keadaan selamat (al-Salamah) dan berterusan/lestari (istiqamah). Hidayat dilihat menzahirkan pola fitrah kesanggupan manusia untuk menerima kebenaran serta ketetapan atau takdir asal manusia mengenai kebahagiaan dan kesesatannya manakala Mek Bongsu menzahirkan pola fitrah potensi dasar manusia untuk beribadat dan perasaan yang tulus ikhlas. Bagi watak antagonis pula, kawasan KKK telah ditawan dan ramai pengikutnya mati terbunuh manakala KKK telah melarikan diri. Melalui analisis, didapati bahawa watak protagonis telah dimenangkan dalam skrip kajian ini bagi memenangkan amal makruf nahi mungkar manakala watak antagonis yang mempertikaikan konsep teater fitrah dalam perjalanan cerita jelas tidak dimenangkan. Kesimpulannya, watak perwatakan yang terdapat dalam drama 'Tiang Seri Tegak Berlima' ini merupakan satu kesinambungan hidup sebagai seorang muslim yang memberi peringatan tentang kebesaran Allah SWT.

\section{RUJUKAN}

Abdul Mujib (1999). Fitrah dan Keperibadian Islam Sebuah Pendekatan Psikologis. Jakarta: PT Raja Grafindo Persada.

Abdul Mujid dan Jusuf Mudzajir (2002). Nuansa-Nuansa Psikologi Islami. Jakarta: PT Raja Grafindo Persada.

Farra Humairah Mohd dan Nik Rafidah Nik Muhammad Affendi. Pemikiran Kerohanian dalam Cerpen Kanakkanak Pilihan Mutakhir dan Kesan Positif kepada Kanak-kanak. PENDETA Journal of Malay Language, Education and Literature. Jilid 7, No.5. (2016): 35-51)

Noordin Hassan. Teater Fitrah. Dewan Sastera. Jilid XIII Bil. 9. September 1983: 3-6

Noordin Hassan (2006). Tiang Seri Tegak Berlima. Noordin Hassan (Ed.) Edisi Khas sasterawan Negara “...demi Zaitun...” Kumpulan Drama Pilihan. Hlm. 216-261.Kuala Lumpur: Dewan Bahasa dan Pustaka.

Rahmah Bujang (2002). Kandungan Semantik Keislaman dalam Drama Malaysia. Halilah Haji Khalid (Ed.). Edisi Khas Sasterawan Negara Teater Fitrah dan Esei Pilihan. Hlm. 3-19. Kuala Lumpur: Dewan Bahasa dan Pustaka.

Salman Al-Farisi. Perempuan Melayu dalam Tiang Seri Tegak Berlima karya Noordin Hassan. Malay Literature. Volume 30, No. 2. (2017): 277-296

Siti Jasmina Ibrahim. (2012). "Titir Kolam Fikir Noordin Hassan" Gambaran Kepengaruhan Positif Karya dan Keperibadiannya kepada Pengarang muda. Kertas kerja Seminar Pemikiran Sasterawan Negara Noordin Hassan. Kuala Lumpur: Dewan Bahasa dan Pustaka. 22-23 Mei 2012

SM Zakir. 'Konsep Teater Fitrah dalam Teater Noordin Hassan'. Pentas. Jilid 2 Bil.3. 2007: 16-23

SM Zakir. 'Fitrah dalam Mitos Mana Setangginya dan Intan yang Tercanai'. Pentas. Jilid 4 Bil. 2. 2009: 17-25

Solehah Ishak. 'Aesthetics of Modern Malay Theatre Productions Which are Predominantly Islamic in Themes'. Malay literature. Vol. 5 No.3 (1989)

Solehah Ishak. 'Theater Fitrah and "1400” *. Malay Literature. Vol. 8 Num. 2 (1995): 14-25

Solehah Ishak. (1996). "Kata Pengantar". Bukan lalang ditiup angin. Kuala Lumpur: Dewan Bahasa dan Pustaka.

Syed Muhammad Naquib Al-Attas. (2010). Islam dan Sekularisme. Indonesia: Institut Pemikiran Islam dan Pembangunan Insan.

Taimiyah, Ibnu, Majmu’. Fatawa, Jilid I, Dar Kutub Al-Ilmiyah. Beirut: Libanon 